\title{
Development of a Modular Didactic Laboratory Set for the Experimental Study of Friction
}

\author{
Jasmina MILJOJKOVIĆ*, Vladimir KOČOVIĆ, Milentije LUKOVIĆ, Aleksandra ŽIVKOVIĆ, Katica ŠIMUNOVIĆ
}

\begin{abstract}
The paper presents the results related to the development of a modular didactic laboratory set for the experimental study of friction and its implementation in engineering education. Successfully implemented in laboratory exercises and research, the modular set has been upgraded over time. A newly developed module is presented for investigating the kinetic coefficient of friction based on the differential equation of motion on an inclined plane. The authors deal with the most critical case - a free fall of a shell-shaped pin down the cylindrical guide when, theoretically, the friction force is equal to zero, while the air resistance force has a maximum value. Based on the time data recorded by inductive sensors, measurements were performed to determine the discrepancy between the theoretical and experimental acceleration values. After introducing the calculation model, the authors quantify very small energy "losses" and analyse the relationship between the unknown resistance force, caused primarily by the imperfections of the experiment, and the air resistance force.
\end{abstract}

Keywords: engineering education; kinetic friction; modular laboratory set

\section{INTRODUCTION}

The role of laboratory exercises in engineering education is to confirm theoretical knowledge, design and conduct experiments, analyse measurement results, and improve skills in equipment handling. Bearing in mind the importance of demonstration experiments [1] and direct handling of devices, setups, and instruments during laboratory exercises [2], students should conduct experiments by themselves as much as possible.

Considering available funds, to provide the conditions for hands-on learning in engineering laboratories, universities often resort to the development of low-cost, dedicated educational setups [3], or use existing modern devices [4], benchmark them [5], or, for example, base their laboratory courses on chorology [6].

In the last decade, many didactic sets and devices have been designed at the Faculty of Engineering in Kragujevac. Students and teachers test, validate, refine, and upgrade those sets over time, developing them from educational tools to equipment that is successfully implemented in laboratory exercises and scientific research. The examples are: a vibroplatform model [7], a device for determining elastic modulus by bending [8], a high-stiffness tool for ball burnishing [9], a novel modular fixture for a flexible manufacturing system [10], small laboratory tensile testing device [11], tribometer for experimental determination of the kinetic friction coefficient [12].Work on designing the educational and research devices generated the idea of developing didactic sets based on a modular principle.

Modular sets consist of mechanical elements, hydraulic, pneumatic, and electrical components, measuring devices of all types, and other elements. Most of the elements and components are standardised or consumer products, so they cost significantly less than specially designed elements. It is possible to form an extensive number of didactic setups and devices for education and research by composing the standard products and developing a relatively small number of specially designed elements. A particular advantage of the concept of modularity lies in the elements' reusability when composing different educational setups, which produces significant technical, technological, and financial effects.
The principle of modularity based on the composition of functional units from standard elements, subassemblies, and assemblies has been present for many years in various technical systems [13]. In university laboratories, the principle of modularity is applied in education in the fields of granular flow [3], electronics [14], control systems [15], learning factories [16], or mechatronics [17]. In addition, leading manufacturers of didactic systems offer a range of complex and high-quality but costly modular sets for university laboratories [18].

Students often experience difficulties perceiving and understanding the essence of the friction phenomenon [19]. Recently published papers indicate that simple but inventive experiments inspired, for example, by a hula hoop [20] or a video game [21], still have an important role in education related to friction, especially on the introductory level. An innovative approach can bring experiments with classic tools to a higher level and produce valuable results. An example is the use of Maxwell's wheel to analyse the nonlinear change in the coefficient of friction as a susceptible quantity [22].

Usually flat, sometimes arbitrarily shaped [23], an inclined plane has been used for a very long time to demonstrate basic sliding and rolling friction concepts. In recent years those experiments are often accompanied by video analysis [24].

Today, computers enable more complex calculations [25] and the application of techniques and methods such as local positioning systems (LPS) for tracking the motion [26] or visuohaptic simulations for analysing the students' reasoning and explanations of friction concepts [27].

Considering that friction, as one of the fundamental problems in physics, has a wide application in different engineering fields, researchers at the Faculty of Engineering (University of Kragujevac) developed a reconfigurable laboratory set consisting of modules for investigating static (sliding and rolling) friction. The set demonstrates the connection between theoretical knowledge and results obtained through experiments during laboratory exercises. In cooperation with researchers from other universities, several papers were published using different modules such as the ones designed for the study of rolling friction at high contact temperatures [28, 29], sliding friction investigations [30], studying the friction in the presence of lubricants [31]. 
After a brief overview of the results related to static friction investigations on the modular set, in this paper, we present a newly developed module for the study of kinetic friction based on the differential equation of motion on an inclined plane. The presented research focuses on the most critical case where the inclination angle is $90^{\circ}$, aiming to verify the new module by performing measurements and introducing a calculation model that enables the quantification of energy "losses" and the analysis of their causes.

\section{CONFIGURATION AND THE FIELD OF IMPLEMENTATION OF THE MODULAR SET}

The set configuration is based on a measuring system and several different modules. Upgrading by adding new modules expands the possibilities of studying the friction phenomenon in the vast field of tribology and tribometry.
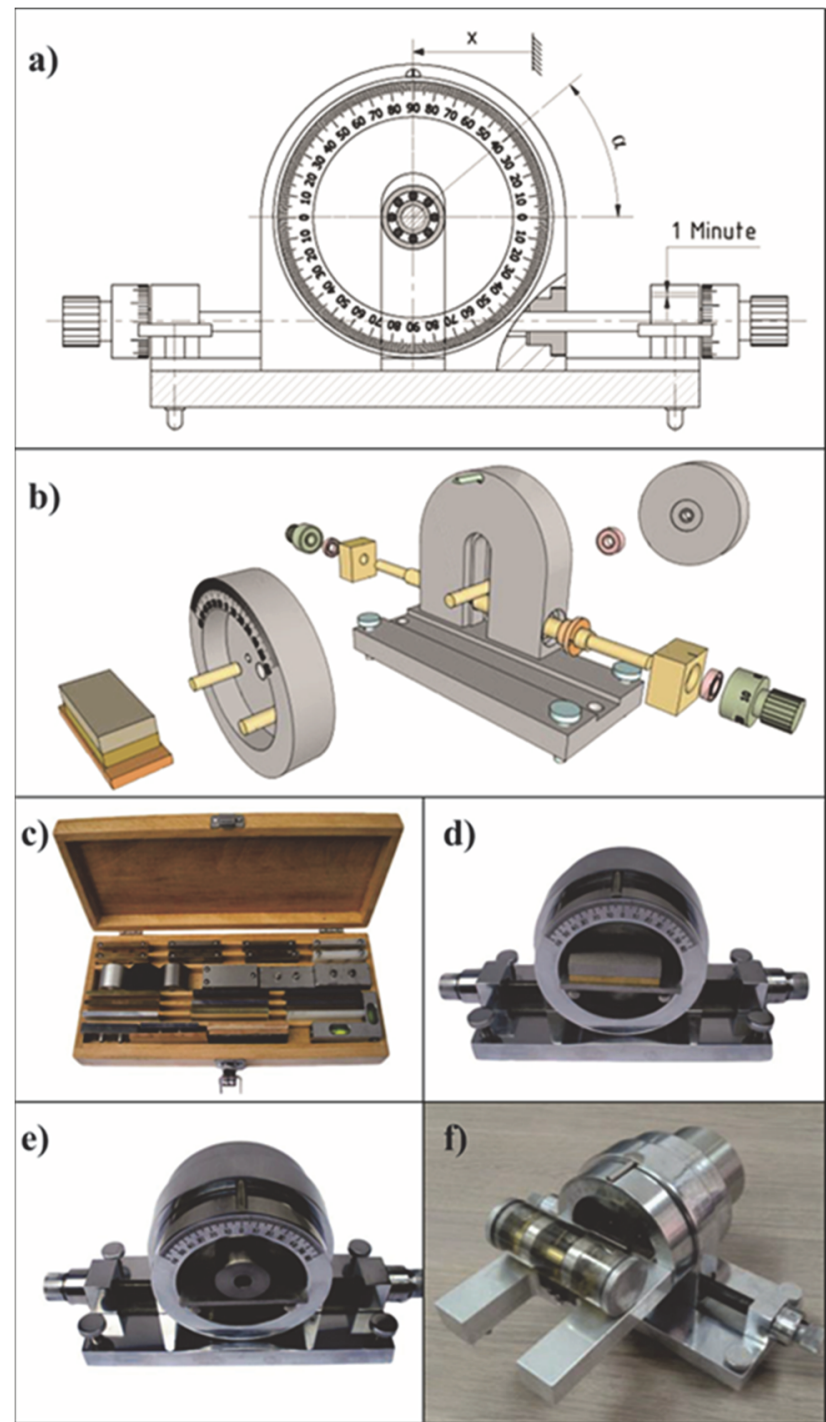

Figure 1 (a) Schematic representation and (b) 3D model of the modular laboratory set [31]; (c) standard test samples [32]; modules for investigations of (d) sliding friction [32], (e) rolling friction [32] and (f) friction in the presence of lubricants [31]

Fig. $1 \mathrm{a}, 1 \mathrm{~b}$ provides a schematic and $3 \mathrm{D}$ representation of the basic set configuration for investigating static sliding and rolling friction. The basis of the set is the measuring system which consists of a precise helical spindle coupled with a nonius calliper fixed at the spindle bearings. This concept of motion transmission enables reliable measurement of the inclination angle with an accuracy of one minute. The measuring system and a set of standard test samples (Fig. 1c) enable the realisation of laboratory exercises in the following fields:

1) Determination of the static coefficient of sliding friction for ten types of materials, at normal load levels of $1 \mathrm{~N}, 2 \mathrm{~N}$, or $3 \mathrm{~N}$, in the conditions of surface contact, line contact, and point contact (Fig. 1d). Additionally, all the experiments can be performed with or without applying different types of lubricants and oils.

2) Determination of the static coefficient of rolling friction for standard rolling elements (balls, cylinders, discs) made of different materials or specially made rolling elements (Fig. 1e). Again, the application of different types of lubricants and oils is optional (Fig. 1f). As in the previous case, the value of the contact surface roughness was accurately determined before the testing.

The set enables the realisation of different experiments related to static sliding and rolling friction and quantification of factors affecting the friction coefficient (material type, normal load level, contact type, lubricant type, surface roughness of contact pairs).

By upgrading the module for investigation of rolling friction to enable testing at higher temperatures (Fig. 2a) or by adding a vacuum pump composed of standard pneumatic components (Fig. 2b) to the basic configuration for the investigation of sliding friction, with a wide range of test samples (Fig. 2c), it is possible to cover with experiments a vast field of the static friction phenomenon. Experiments in the conditions of controlled contact temperature and vacuum depth (Fig. 2d) can be performed for both educational and scientific purposes.

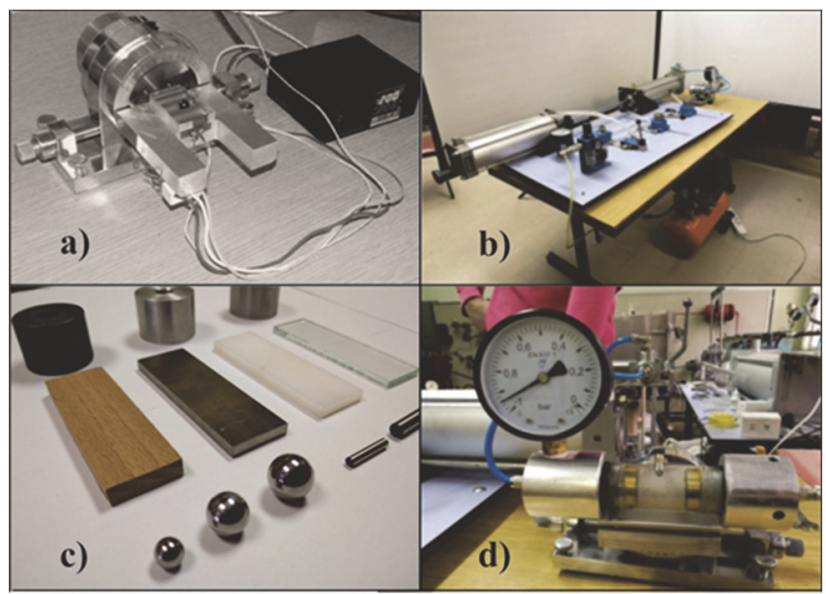

Figure 2 (a) Module for investigations at higher temperatures [29]; (b) vacuum pump; (c) examples of test samples; (d) module for investigations at controlled vacuum depth

The scope of the modular set application was further expanded to the investigation of kinetic friction. A newly developed module is described in the next chapter.

\section{CONFIGURATION OF THE MODULE FOR INVESTIGATIONS IN THE FIELD OF KINETIC FRICTION}

Photographs of the newly developed module added to the basic configuration are provided in Fig. 3. The module can be placed in different positions, i.e. at different angles 
relative to the horizontal plane (Fig. 3a, 3b). The authors intended to determine the kinetic coefficient of friction experimentally, based on the differential equation of body motion down an inclined plane in the presence of frictional and air resistance forces. It should be emphasised that Leonhard Euler laid the theoretical foundations of this method in $1748[33,34]$ and that the authors based some of their previous kinetic friction investigations on Euler's approach [7, 12].

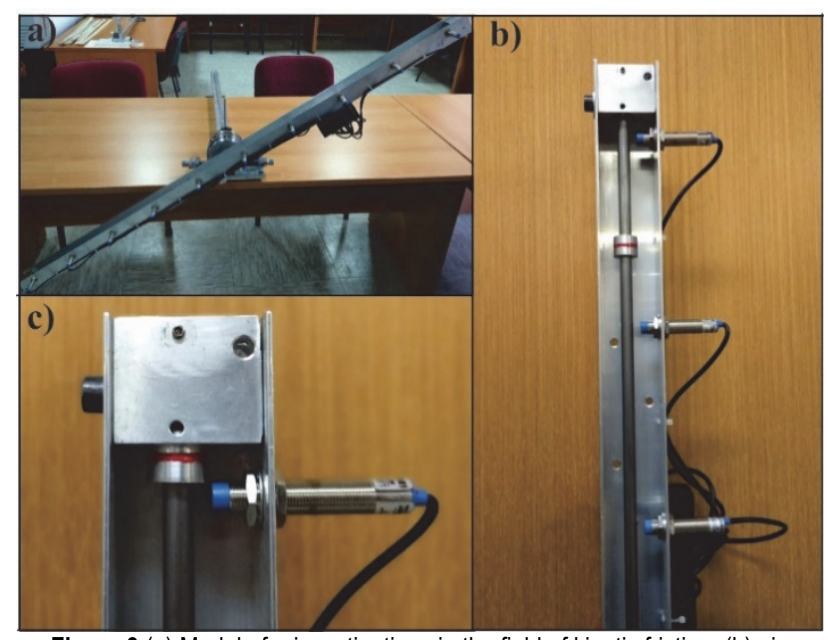

Figure 3 (a) Module for investigations in the field of kinetic friction; (b) pin moving down the cylindrical guide vertical position; (c) cylindrical pin and the first sensor.

In previous investigations [12], where the theoretical model considered the inclination angle $\alpha$ to be less than $90^{\circ}$, the authors introduced the coefficient $\xi$ as the ratio between the air resistance force and friction force:

$$
\xi=\frac{C_{\mathrm{D}} \cdot \rho_{\mathrm{w}} \cdot v^{2}}{2 \cdot \mu \cdot \rho_{\mathrm{m}} \cdot L \cdot \mathrm{g} \cdot \cos \alpha}
$$

where $C_{\mathrm{D}}$ denotes the drag coefficient as the function of flow velocity, flow direction, body position, body size, fluid density, and fluid viscosity; $\rho_{w}$ denotes the air density; $\rho_{m}, L$ and $v$ are the density, the length, and the velocity of the body, respectively; $\mu$ is the friction coefficient; $\mathrm{g}$ is the gravitational acceleration; $\alpha$ is the inclination angle.

When considering the case of a stainless steel body sliding down an inclined plane, the ratio between the air resistance force and friction force equals

$$
\xi \approx 1.3 \cdot 10^{-4} \frac{v^{2}}{\mu \cdot \cos \alpha}, \mathrm{m}^{2} / \mathrm{s}^{2}
$$

Based on Eq. (2), it can be concluded that the influence of the air resistance force can be neglected at lower velocities and relatively higher values of the coefficient of sliding friction. However, at higher velocities, especially in rolling friction investigations, the air resistance must be considered because it could significantly affect the results. For example, at a velocity of $3 \mathrm{~m} / \mathrm{s}$, when the inclination angle is $30^{\circ}$, considering that the coefficient of rolling friction is of the order of $10^{-2}, \xi$ equals 0,136 .
In this paper, we analyse the most critical case when $\alpha=90^{\circ}$. Theoretically, the friction force is then equal to zero, and the air resistance force has a maximum value. The relationship between the unknown resistance force and the air resistance force during the free fall of the pin (hollow cylinder or shell) along the cylindrical guide is analysed.

Measurement of gravitational acceleration is often included in introductory mechanics, but the effects of air resistance are rarely discussed with students [25]. In addition to air resistance, this paper aims to analyse the effects of resistances caused primarily by the imperfections of the experiment (such as geometric imperfections of the cylindrical guide and the pin, possible micro-impacts, deviation of the cylindrical guide axis relative to the ideal vertical axis). In this paper, errors in the determined acceleration values are of the same order as in [25], where photogates were used and only the air resistance force was taken into account.

Here, we present the calculation model through the example of experimental determination of gravitational acceleration at resistances caused primarily by the imperfections of the experiment.

\section{EXPERIMENTAL INVESTIGATIONS}

The method is based on the experimental determination of the distance function, i.e. on discrete measurement of time in specific points during the body's free fall from a height of 1,408 $\mathrm{m}$.

The pin (hollow cylinder or shell) begins to fall along the cylindrical guide (Figs. 3b, 3c and 4) with zero initial velocity $v_{0}=0$. The first inductive sensor $\left(I S_{0}\right)$, after the distance $s_{0}=0,018 \mathrm{~m}$, detects the body passing through its reaction zone and records the zero time, i.e. assigns it a zero value. The second inductive sensor $\left(I S_{1}\right)$ is $0,154 \mathrm{~m}$ below the first sensor and records the time $t_{1}$ with an accuracy of 0,001 s. All subsequent sensors $\left(I S_{2} \div I S_{9}\right)$ quantify the times on the remaining equal sections of 0,154 m.

The measurement scheme, sensor positions and graphical illustration of the time values recorded when the pin passed through the sensors' reaction zones, as well as the limits of scattering of the time measurement results in the range $\pm 3 \sigma$, where $\sigma$ is standard deviation, are given in Fig. 4. The widths of the circular rings correspond to the time results $\left(t_{0} \div t_{9}\right)$ scattering within $\pm 3 \sigma$.

Thirty independent experiments were conducted, followed by nonlinear regression analysis of the measurement results using the software package Statistica. The pin travels the distance $s_{0}$ before reaching the first sensor, i.e. before the measurement of time starts (Fig. 3c). Although $I S_{0}$ assigned $t_{0}$ a value zero, $t_{0}$ does have a certain value that needs to be estimated and added to every subsequent recorded time. As a basic regression function, the theoretical distance function was adopted in the following form

$s=\frac{1}{2} \cdot a \cdot\left(t+t_{0}\right)^{2}$ 
In Eq. (3), the acceleration $a$ and the time $t_{0}$ are estimated values, i.e. outputs of the regression analysis. Very high correlation coefficients $(R>0,996)$ and low values of residuals characterise all thirty regression equations obtained by data processing. The estimated values of time $t_{0}$ had a relatively small scattering, while the values of the obtained acceleration ranged from 8,36 to $9,32 \mathrm{~m} / \mathrm{s}$.

The final processing of the results of thirty experiments was performed using mean values of time $t_{\mathrm{m}}$ and standard deviations of time $\sigma_{t}$ associated with each sensor. The mean values of estimated time $t_{0}$ and its standard deviation $\sigma_{t_{0}}$ were calculated based on regression analysis of data obtained in thirty experiments.

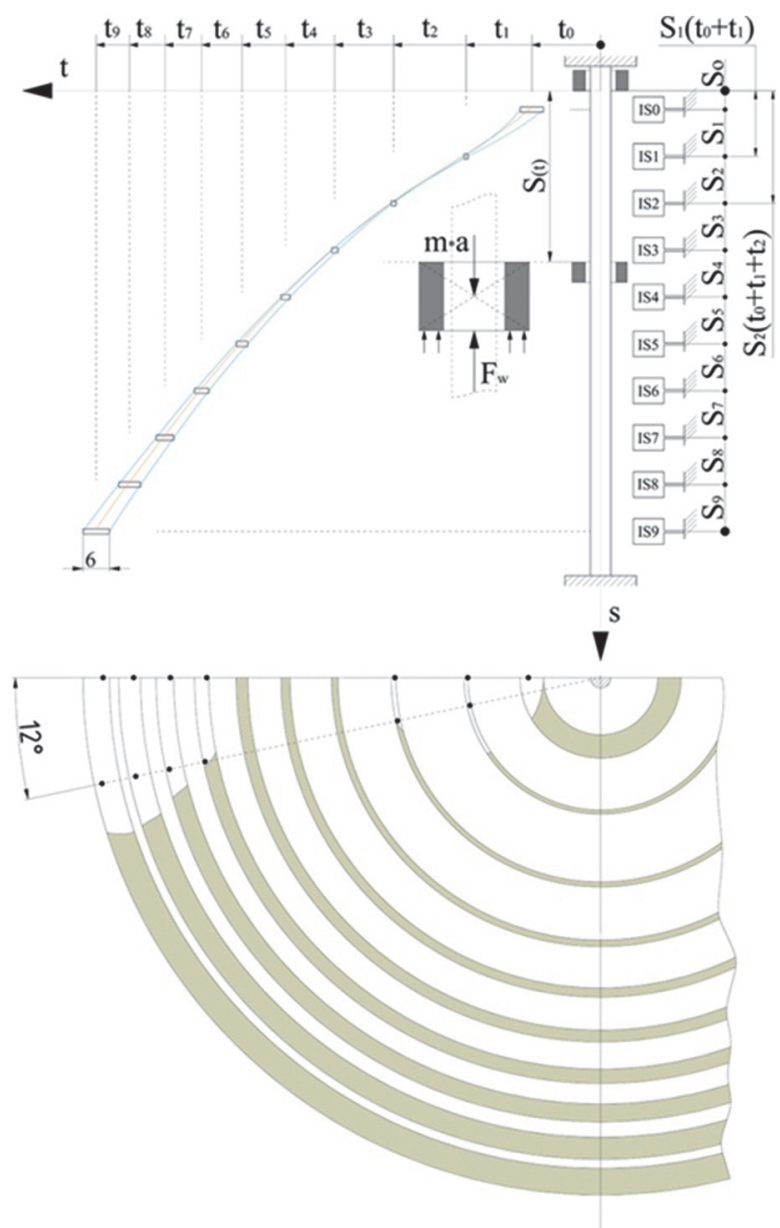

Figure 4 Measurement scheme and graphical illustration of the results

The values of $t_{\mathrm{m}},\left(t_{\mathrm{m}}+3 \sigma_{t_{\mathrm{m}}}\right)$ and $\left(t_{\mathrm{m}}-3 \sigma_{t_{\mathrm{m}}}\right)$ for each sensor (Tab. 1) contain the now known time $t_{0 \mathrm{~m}}$, so the nonlinear regression analysis is performed with the base function of the form

$$
S_{\text {reg }(t)}=\frac{1}{2} \cdot 9,81 \cdot C_{1} \cdot t^{2}
$$

By differentiating the regression equations of the distance function with respect to time, we get the velocity function for $t_{\mathrm{m}},\left(t_{\mathrm{m}}+3 \sigma_{t_{\mathrm{m}}}\right)$ and $\left(t_{\mathrm{m}}-3 \sigma_{t_{\mathrm{m}}}\right)$ :

$v_{\text {reg }(t)}=\frac{\mathrm{d} s_{\text {reg }(t)}}{\mathrm{d} t}=9,81 \cdot C_{1} \cdot t$

The acceleration values for $t_{\mathrm{m}},\left(t_{\mathrm{m}}+3 \sigma_{t_{\mathrm{m}}}\right)$ and $\left(t_{\mathrm{m}}-3 \sigma_{t_{\mathrm{m}}}\right)$ are determined based on the Eq. (6).

$a_{\text {reg }(t)}=\mathrm{g}-k \cdot v_{\text {reg }(t)}^{2}$

The coefficient $k$ equals

$k=\frac{1}{2 \cdot m} \cdot C_{\mathrm{D}} \cdot \rho_{\mathrm{w}} \cdot A$

where $m$ is the mass of the pin $(0,010179 \mathrm{~kg}), \rho_{\mathrm{w}}$ is the air density (app. $1 \mathrm{~kg} / \mathrm{m}^{3}$ ), $C_{\mathrm{D}}$ is the aerodynamic coefficient as the function of the body shape $(0,5)$, and $A$ is the area of the pin's projection on a plane normal to the direction of motion $\left(0,0002353 \mathrm{~m}^{2}\right)$.

Using the known theoretical laws of free fall with air resistance [35] and Eqs. (8), (9) and (11), we can determine theoretical values of the distance function, velocity function and acceleration function, respectively. Furthermore, we can analyse the discrepancy between the theoretical and experimentally obtained quantities.

The theoretical values of distance $s_{\mathrm{th}(t)}$, for $t_{\mathrm{m}}$, $\left(t_{\mathrm{m}}+3 \sigma_{t_{\mathrm{m}}}\right)$ and $\left(t_{\mathrm{m}}-3 \sigma_{t_{\mathrm{m}}}\right)$, are defined by the Eq. (8).

$s_{\mathrm{th}(t)}=\frac{k_{1}^{2}}{\mathrm{~g}} \cdot \ln \left[\cos h\left(\frac{\mathrm{g} \cdot t}{k_{1}}\right)\right]$

Eq. (9) defines the theoretical values of velocity $v_{\text {th }(t)}$ for $t_{\mathrm{m}},\left(t_{\mathrm{m}}+3 \sigma_{t_{\mathrm{m}}}\right)$ and $\left(t_{\mathrm{m}}-3 \sigma_{t_{\mathrm{m}}}\right)$.

$v_{\text {th }(t)}=k_{1} \cdot \tan h\left(\frac{\mathrm{g}}{k_{1}} \cdot t\right)$

The coefficient $k_{1}$ in Eq. (8) and (9) equals

$k_{1}=\sqrt{\frac{2 \cdot m \cdot \mathrm{g}}{C_{\mathrm{D}} \cdot \rho_{\mathrm{w}} \cdot A}}$

Finally, Eq. (11) defines the theoretical values of acceleration $a_{\mathrm{th}(t)}$ for $t_{\mathrm{m}},\left(t_{\mathrm{m}}+3 \sigma_{t_{\mathrm{m}}}\right)$ and $\left(t_{\mathrm{m}}-3 \sigma_{t_{\mathrm{m}}}\right)$.

$a_{\mathrm{th}(t)}=\mathrm{g}-k \cdot v_{\mathrm{th}(t)}^{2}$ 


\section{RESULTS AND DISCUSSION}

Relative errors of the distance travelled, velocity and acceleration in relation to the values obtained by statistical processing of experimental results are determined based on Eq. (12), (13) and (14), respectively, for $t_{\mathrm{m}},\left(t_{\mathrm{m}}+3 \sigma_{t_{\mathrm{m}}}\right)$ and $\left(t_{\mathrm{m}}-3 \sigma_{t_{\mathrm{m}}}\right)$.

$\varepsilon s_{(t)}=\frac{\left[s_{\operatorname{th}(t)}-s_{\operatorname{reg}(t)}\right]}{s_{\operatorname{th}(t)}}$

$\varepsilon v_{(t)}=\frac{\left[v_{\operatorname{th}(t)}-v_{\operatorname{reg}(t)}\right]}{v_{\operatorname{th}(t)}}$

$\varepsilon a_{(t)}=\frac{\left[a_{\mathrm{th}(t)}-a_{\mathrm{reg}(t)}\right]}{a_{\mathrm{th}(t)}}$

Relative errors of the measured, i.e. the actual value of the distance travelled $s_{i}$, in relation to the values obtained by regression analysis, were calculated using Eq. (15). As in previous calculations, the scattering of $t_{\mathrm{m}}$ in the interval $\pm 3 \sigma$ was taken into account.

$\varepsilon s_{i(t)}=\frac{\left[s_{i}-s_{\text {reg }(t)}\right]}{s_{i}}$

Graphical representations of the theoretical value of acceleration $a_{\text {th }\left(t_{\mathrm{m}}\right)}$ and experimentally obtained values $a_{\mathrm{reg}\left(t_{\mathrm{m}}\right)}, a_{\mathrm{reg}\left(t_{\mathrm{m}}+3 \sigma\right)}$ and $a_{\mathrm{reg}\left(t_{\mathrm{m}}-3 \sigma\right)}$ are given in Fig. 5.

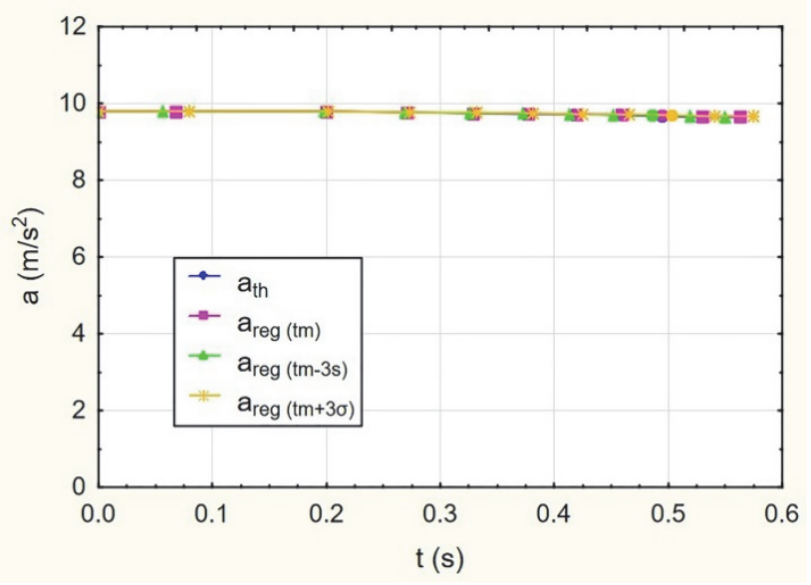

Figure $\mathbf{5}$ The theoretical and experimentally obtained values of acceleration

Diagrams of relative errors of acceleration $\varepsilon a_{\left(t_{\mathrm{m}}\right)}$, $\varepsilon a_{\left(t_{\mathrm{m}}+3 \sigma\right)}$ and $\varepsilon a_{\left(t_{\mathrm{m}}-3 \sigma\right)}$ in relation to the theoretical acceleration are provided in Fig. 6.

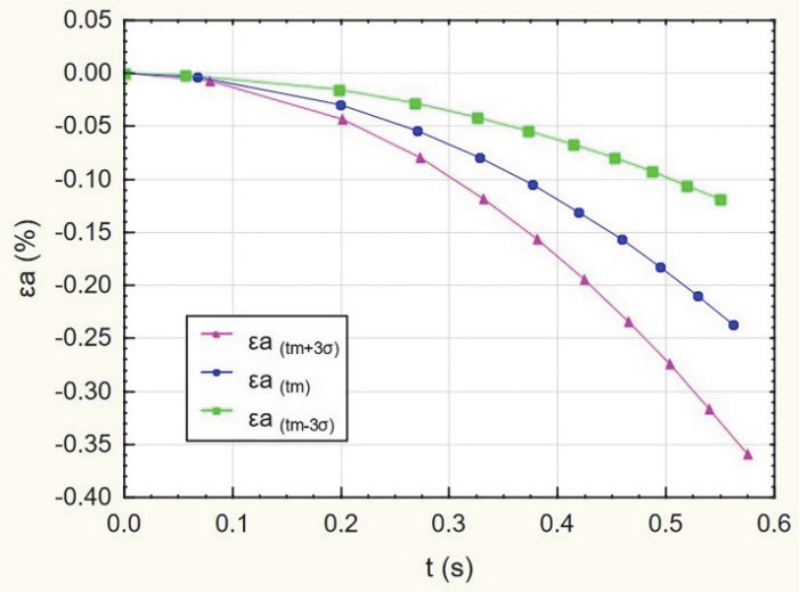

Figure 6 Relative errors of acceleration

The distance, velocity, and acceleration values obtained by regression analysis have relatively small deviations from their theoretical values. Relative error of the distance travelled is in the interval $8,4 \div 8,7 \%$, the velocity error is approximately $7 \%$, while the calculated acceleration does not deviate more than $0,24 \%$ from its theoretical value on the entire distance of $1,408 \mathrm{~m}$.

The error of predicted distance in relation to the actual, measured value only occurs when the motion is initiated, and it rapidly decreases from approximately

$13 \%$ to less than $1 \%$ in $0,33 \mathrm{~m}$. The initial error of $13 \%$ corresponds to an absolute error of $2,34 \mathrm{~mm}$ in the estimation of an $18 \mathrm{~mm}$ long section $s_{0}$.

The discussed errors were observed based on the mean time values $t_{\mathrm{m}}$ as, statistically, the most probable errors. The calculations and diagrams also indicate the limits of errors calculated based on the mean values of time within the range $\left(t_{\mathrm{m}}+3 \sigma_{t_{\mathrm{m}}}\right)$. The theoretical values of distance, velocity and acceleration are completely limited by this area of scattering of the time values, with $t_{\mathrm{m}}$ as the mathematical expectation and the central tendency of the results.

The total energy "losses" ( $\left.E_{\mathrm{t}}\right)$ have small values and can be determined based on the difference between the total mechanical energy at the beginning of the motion and the energy at the end of 1,408 $\mathrm{m}$ long distance $s$, using Eq. (16).

$$
E_{\mathrm{t}}=m \cdot \mathrm{g} \cdot s-\frac{1}{2} m \cdot v^{2}=0,01177 \mathrm{~J}
$$

Energy "losses" are equal to the sum of the work done by the air resistance force and the works done by other forces disrupting the motion. Those forces are related to deviations of the actual path of the pin moving down the cylindrical guide from the ideal vertical path, possible rotation of the pin caused by the initiation of motion, possible micro-impacts, occasional friction, and geometric imperfections of the guide and the pin.

The total energy 'loss' equals:

$$
E_{\mathrm{t}}=\int_{0}^{s}\left(F_{\mathrm{e}}^{*}+F_{\mathrm{w}}\right) \cdot \mathrm{d} s=0,01177 \mathrm{~J}
$$


where $F_{\mathrm{e}}^{*}$ is the unknown force generated from the imperfections of the experiment, i.e. the disruptive factors mentioned above, while $F_{\mathrm{w}}$ is the air resistance force.
Energy "loss" caused by the air resistance equals:

$$
E_{\mathrm{w}}=\frac{1}{2} \cdot C \cdot \rho \cdot A \cdot \int_{0}^{s} v^{2} \cdot \mathrm{d} s=\int_{0}^{s} F_{\mathrm{w}} \cdot \mathrm{d} s=0,00098 \mathrm{~J}
$$

Table 1 Results of the experiments

\begin{tabular}{|c|c|c|c|c|c|c|c|c|c|c|}
\hline Sensor & $I S_{0}$ & $I S_{1}$ & $I S_{2}$ & $I S_{3}$ & $I S_{4}$ & $I S_{5}$ & $I S_{6}$ & $I S_{7}$ & $I S_{8}$ & $I S_{9}$ \\
\hline$t_{\mathrm{m}} / \mathrm{s}$ & 0,067 & 0,199 & 0,270 & 0,328 & 0,377 & 0,419 & 0,459 & 0,495 & 0,529 & 0,562 \\
\hline$t_{\mathrm{m}}+3 \sigma / \mathrm{s}$ & 0,079 & 0,201 & 0,273 & 0,331 & 0,381 & 0,425 & 0,466 & 0,503 & 0,540 & 0,575 \\
\hline$t_{\mathrm{m}}-3 \sigma / \mathrm{s}$ & 0,056 & 0,198 & 0,268 & 0,325 & 0,372 & 0,414 & 0,452 & 0,486 & 0,519 & 0,549 \\
\hline$s_{i} / \mathrm{m}$ & 0,018 & 0,172 & 0,327 & 0,481 & 0,636 & 0,790 & 0,945 & 1,099 & 1,254 & 1,408 \\
\hline $\begin{array}{c}S_{\text {reg }\left(t_{\mathrm{m}}\right)} / \mathrm{m} \\
C_{1}=0,912466 ; R=0,9999762\end{array}$ & 0,020 & 0,178 & 0,327 & 0,482 & 0,635 & 0,786 & 0,942 & 1,095 & 1,254 & 1,414 \\
\hline $\begin{array}{c}S_{\mathrm{reg}\left(t_{\mathrm{m}}+3 \sigma\right)} / \mathrm{m} \\
C_{2}=0,880336 ; R=0,99981\end{array}$ & 0,027 & 0,175 & 0,321 & 0,474 & 0,626 & 0,779 & 0,936 & 1,094 & 1,259 & 1,427 \\
\hline $\begin{array}{c}S_{\mathrm{reg}\left(t_{\mathrm{m}}-3 \sigma\right)} / \mathrm{m} \\
C_{3}=0,946212 ; R=0,9999235\end{array}$ & 0,015 & 0,181 & 0,334 & 0,491 & 0,643 & 0,794 & 0,948 & 1,097 & 1,249 & 1,401 \\
\hline$v_{\mathrm{reg}\left(t_{\mathrm{m}}\right)} / \mathrm{m} / \mathrm{s}$ & 0,604 & 1,786 & 2,422 & 2,940 & 3,372 & 3,754 & 4,109 & 4,431 & 4,741 & 5,034 \\
\hline$v_{\operatorname{reg}\left(t_{\mathrm{m}}+3 \sigma\right)} / \mathrm{m} / \mathrm{s}$ & 0,681 & 1,739 & 2,356 & 2,861 & 3,289 & 3,669 & 4,021 & 4,346 & 4,663 & 4,965 \\
\hline$v_{\mathrm{reg}\left(t_{\mathrm{m}}-3 \sigma\right)} / \mathrm{m} / \mathrm{s}$ & 0,520 & 1,833 & 2,489 & 3,018 & 3,455 & 3,839 & 4,194 & 4,513 & 4,816 & 5,099 \\
\hline$a_{\mathrm{reg}\left(t_{\mathrm{m}}\right)} / \mathrm{m} / \mathrm{s}^{2}$ & 9,808 & 9,792 & 9,776 & 9,760 & 9,744 & 9,729 & 9,712 & 9,697 & 9,680 & 9,664 \\
\hline$a_{\mathrm{reg}\left(t_{\mathrm{m}}+3 \sigma\right)} / \mathrm{m} / \mathrm{s}^{2}$ & 9,807 & 9,793 & 9,778 & 9,763 & 9,747 & 9,732 & 9,717 & 9,701 & 9,684 & 9,668 \\
\hline$a_{\mathrm{reg}\left(t_{\mathrm{m}}-3 \sigma\right)} / \mathrm{m} / \mathrm{s}^{2}$ & 9,808 & 9,791 & 9,774 & 9,757 & 9,741 & 9,725 & 9,708 & 9,692 & 9,676 & 9,660 \\
\hline$S_{\mathrm{th}\left(t_{\mathrm{m}}\right)} / \mathrm{m}$ & 0,022 & 0,195 & 0,359 & 0,528 & 0,695 & 0,860 & 1,030 & 1,198 & 1,371 & 1,545 \\
\hline$S_{\mathrm{th}\left(t_{\mathrm{m}}+3 \sigma\right)} / \mathrm{m}$ & 0,031 & 0,199 & 0,365 & 0,538 & 0,711 & 0,884 & 1,061 & 1,239 & 1,426 & 1,616 \\
\hline$S_{\mathrm{th}\left(t_{\mathrm{m}}-3 \sigma\right)} / \mathrm{m}$ & 0,015 & 0,191 & 0,352 & 0,518 & 0,679 & 0,838 & 1,000 & 1,157 & 1,317 & 1,476 \\
\hline$v_{\mathrm{th}\left(t_{\mathrm{m}}\right)} / \mathrm{m} / \mathrm{s}$ & 0,649 & 1,920 & 2,604 & 3,161 & 3,626 & 4,036 & 4,417 & 4,764 & 5,097 & 5,412 \\
\hline$v_{\mathrm{th}\left(t_{\mathrm{m}}+3 \sigma\right)} / \mathrm{m} / \mathrm{s}$ & 0,759 & 1,939 & 2,627 & 3,190 & 3,667 & 4,090 & 4,483 & 4,846 & 5,199 & 5,535 \\
\hline$v_{\mathrm{th}\left(t_{\mathrm{m}}-3 \sigma\right)} / \mathrm{m} / \mathrm{s}$ & 0,539 & 1,902 & 2,582 & 3,131 & 3,584 & 3,982 & 4,351 & 4,681 & 4,996 & 5,290 \\
\hline$a_{\mathrm{th}\left(t_{\mathrm{m}}\right)} / \mathrm{m} / \mathrm{s}^{2}$ & 9,808 & 9,789 & 9,771 & 9,752 & 9,734 & 9,716 & 9,697 & 9,679 & 9,660 & 9,641 \\
\hline$a_{\mathrm{th}\left(t_{\mathrm{m}}+3 \sigma\right)} / \mathrm{m} / \mathrm{s}^{2}$ & 9,807 & 9,788 & 9,770 & 9,751 & 9,732 & 9,713 & 9,694 & 9,674 & 9,654 & 9,633 \\
\hline$a_{\mathrm{th}\left(t_{\mathrm{m}}-3 \sigma\right)} / \mathrm{m} / \mathrm{s}^{2}$ & 9,808 & 9,789 & 9,771 & 9,753 & 9,736 & 9,718 & 9,701 & 9,683 & 9,666 & 9,648 \\
\hline$\varepsilon s_{\left(t_{\mathrm{m}}\right)} / \%$ & 8,699 & 8,669 & 8,640 & 8,611 & 8,581 & 8,552 & 8,522 & 8,493 & 8,462 & 8,431 \\
\hline$\varepsilon s_{\left(t_{\mathrm{m}}+3 \sigma\right)} / \%$ & 11,961 & 11,933 & 11,905 & 11,875 & 11,846 & 11,816 & 11,786 & 11,756 & 11,724 & 11,692 \\
\hline$\varepsilon s_{\left(t_{\mathrm{m}}-3 \sigma\right)} / \%$ & 5,376 & 5,344 & 5,315 & 5,284 & 5,255 & 5,226 & 5,196 & 5,168 & 5,139 & 5,109 \\
\hline$\varepsilon v_{\left(t_{\mathrm{m}}\right)} / \%$ & 6,985 & 6,985 & 6,985 & 6,985 & 6,985 & 6,985 & 6,985 & 6,985 & 6,985 & 6,985 \\
\hline$\varepsilon v_{\left(t_{\mathrm{m}}+3 \sigma\right)} / \%$ & 10,309 & 10,309 & 10,309 & 10,309 & 10,309 & 10,309 & 10,309 & 10,309 & 10,309 & 10,309 \\
\hline$\varepsilon v_{\left(t_{\mathrm{m}}-3 \sigma\right)} / \%$ & 3,597 & 3,597 & 3,597 & 3,597 & 3,597 & 3,597 & 3,597 & 3,597 & 3,597 & 3,597 \\
\hline$\varepsilon a_{\left(t_{\mathrm{m}}\right)} / \%$ & $-0,003$ & $-0,029$ & $-0,054$ & $-0,080$ & $-0,105$ & $-0,131$ & $-0,157$ & $-0,183$ & $-0,210$ & $-0,237$ \\
\hline$\varepsilon a_{\left(t_{\mathrm{m}}+3 \sigma\right)} / \%$ & $-0,007$ & $-0,043$ & $-0,080$ & $-0,118$ & $-0,156$ & $-0,195$ & $-0,234$ & $-0,274$ & $-0,316$ & $-0,359$ \\
\hline$\varepsilon a_{\left(t_{\mathrm{m}}-3 \sigma\right)} / \%$ & $-0,001$ & $-0,015$ & $-0,028$ & $-0,041$ & $-0,054$ & $-0,067$ & $-0,080$ & $-0,092$ & $-0,105$ & $-0,118$ \\
\hline$\varepsilon s_{i\left(t_{\mathrm{m}}\right)} / \%$ & $-13,190$ & $-3,273$ & $-0,201$ & $-0,242$ & 0,134 & 0,420 & 0,239 & 0,280 & $-0,121$ & $-0,491$ \\
\hline$\varepsilon S_{i\left(t_{\mathrm{m}}+3 \sigma\right)} / \%$ & $-49,254$ & $-1,502$ & 1,708 & 1,527 & 1,477 & 1,395 & 0,902 & 0,498 & $-0,441$ & $-1,346$ \\
\hline$\varepsilon s_{i\left(t_{\mathrm{m}}-3 \sigma\right)} / \%$ & 19,067 & $-4,991$ & $-2,068$ & $-1,962$ & $-1,138$ & $-0,465$ & $-0,321$ & 0,183 & 0,340 & 0,523 \\
\hline
\end{tabular}

Tab. 1 contains the results obtained based on the time measured on known sections of the total distance (Fig. 4) and the values calculated using Eqs. (4) to (15).
The velocity and the distance increment are calculated using Eq. (19) and Eq. (20).The value of constant $C_{1}$ is 0,9124 (Tab. 1). 


$$
\begin{aligned}
& v_{\operatorname{reg}\left(t_{\mathrm{m}}\right)}=\frac{\mathrm{d} s_{\text {reg }\left(t_{\mathrm{m}}\right)}}{\mathrm{d} t}=9,81 \cdot C_{1} \cdot t_{\mathrm{m}} \\
& \mathrm{d} s_{\text {reg }\left(t_{\mathrm{m}}\right)}=\mathrm{d}\left(\frac{1}{2} \cdot 9,81 \cdot C_{1} \cdot t_{\mathrm{m}}^{2}\right)=9,81 \cdot C_{1} \cdot t_{\mathrm{m}} \cdot \mathrm{d} t_{\mathrm{m}}
\end{aligned}
$$

Based on the given equations, energy "loss" caused by the imperfections of the experiment is equal to

$$
E_{\mathrm{e}}^{*}=\int_{0}^{s} F_{\mathrm{e}}^{*} \cdot \mathrm{d} s=E_{\mathrm{t}}-E_{\mathrm{w}}=0.01079 \mathrm{~J}
$$

The share of air resistance in total energy 'loss' is $8,33 \%$, while an unknown force of stochastic character $F_{\mathrm{e}}^{*}$ causes most of the "losses" (91,6\%).

The smallness of the energy "loss" of $0,01079 \mathrm{~J}$ can be illustrated by the fact that it corresponds to the energy generated by the mass of only $0,78 \mathrm{~g}$ during a free fall ( $\mathrm{g}=9,81 \mathrm{~m} / \mathrm{s}^{2}$ ) from the same height as in the described experiment ( $s=1,408 \mathrm{~m})$.

\section{CONCLUSIONS}

Based on the material presented in the paper, it can be concluded:

1) Students often experience difficulties perceiving and understanding the friction phenomenon. A reconfigurable set for investigating static and kinetic sliding and rolling friction might be the appropriate solution. The development of different modules and implementation of the set in laboratory exercises allow students to design experiments, perform necessary measurements, and statistically process and analyse the results.

2) By composing the standard elements and a relatively small number of specially designed elements, an extensive number of setups and devices for education and research can be created. A particular advantage of the concept of modularity lies in the elements' reusability when composing different educational setups, which produces significant technical, technological, and financial effects.

3) The presented results of the kinetic friction investigation based on an inclined plane in the most critical case $\left(\alpha=90^{\circ}\right)$ prove that very small energy "losses" can be quantified based on the differential equation of motion.

4) The imperfections of the experiment have caused energy "loss" of 0,01079 J. The quantified energy 'loss' due to the effect of air resistance of $0,00098 \mathrm{~J}$ corresponds to the energy generated by a mass of only $0,071 \mathrm{~g}$ during a free fall from a height of $1,408 \mathrm{~m}$.

6) The values of energy 'losses' presented in the paper indicate that the method itself, which dates back to Leonard Euler's time, has great potential. However, one could not say that it has a significant role in the field of industrial tribometry.

7) The authors consider that the method has significant advantages over other tribometric methods, not only in terms of using the method for educational and research purposes but also in terms of results' reliability.

8) In addition to the verification of educational benefits from the modular set and further improvements of the set, future research should focus on the possibilities of applying the presented method in nanotribometry and industrial tribometric problems considering that the method allows the covering of a broad velocity spectrum under the same contact conditions.

\section{Acknowledgements}

The authors thank Branko Tadic, professor at the Faculty of Engineering (University of Kragujevac, Serbia), who provided insight and expertise that greatly assisted the research.

\section{Nomenclature}

$A$

$a_{\text {reg }\left(t_{\mathrm{m}}\right)}, a_{\mathrm{th}\left(t_{\mathrm{m}}\right)}$

$C_{\mathrm{D}}$

$E_{\mathrm{t}}, E_{\mathrm{w}}, E_{\mathrm{e}}^{*}$

$F_{\mathrm{e}}^{*}, F_{\mathrm{w}}$

$\mathrm{g}$

IS

$L$

$s_{i}, S_{\text {reg }\left(t_{\mathrm{m}}\right)}$,

$S_{\mathrm{th}\left(t_{\mathrm{m}}\right)}$

$t_{i}, t_{\mathrm{m}}$

$v_{\text {reg }\left(t_{\mathrm{m}}\right)}, v_{\mathrm{th}\left(t_{\mathrm{m}}\right)}$

$\alpha$

$\varepsilon s_{i\left(t_{\mathrm{m}}\right)}, \varepsilon s_{\left(t_{\mathrm{m}}\right)}$,

$\varepsilon v_{\left(t_{\mathrm{m}}\right)}, \varepsilon a_{\left(t_{\mathrm{m}}\right)}$

$\mu$

$\rho_{\mathrm{w}}, \rho_{\mathrm{m}}$

$\sigma_{t_{\mathrm{m}}}$

$\xi$
Area of the body's projection on a plane normal to the direction of motion $/ \mathrm{m}^{2}$

Acceleration as an output of non linear regression, theoretical acceleration $/ \mathrm{m} / \mathrm{s}^{2}$

Drag coefficient / -

Energy "loss" - total, caused by the air resistance, caused by the imperfections of the experiment / J

Force generated from the imperfections of the experiment, air resistance force / $\mathrm{N}$

Gravitational acceleration $/ \mathrm{m} / \mathrm{s}^{2}$

Inductive sensor

Length of the body / $\mathrm{m}$

Distance - measured value, an output of nonlinear regression, theoretical value / $\mathrm{m}$

Time recorded by sensors increased by estimated time $t_{0}$, the mean value of time / $\mathrm{s}$

Velocity as an output of non linear regression, theoretical velocity $/ \mathrm{m} / \mathrm{s}$ Inclination angle $/{ }^{\circ}$

Relative errors of the measured distance, theoretical distance, theoretical velocity and theoretical acceleration, in relation to the values obtained by statistical processing / $\%$ Friction coefficient / -

Air and body density $/ \mathrm{kg} / \mathrm{m}^{3}$

Standard deviation of the mean value of time / s

Ratio between the air resistance force and friction force / -

\section{REFERENCES}

[1] Bartoš, J. \& Musilová, J. (2004). Small surprises in 'rollingphysics' experiments. European Journal of Physics, 25(5), 675. https://doi.org/10.1088/0143-0807/25/5/010

[2] Nikolic, S., Ritz, C., Vial, P. J., Ros, M., \& Stirling, D. (2015). Decoding student satisfaction: How to manage and improve the laboratory experience. IEEE Transactions on Education, 58(3), 151-158. https://doi.org/10.1109/te.2014.2346474 
[3] Heinze, T. (2020). A highly flexible laboratory setup to demonstrate granular flow characteristics. Natural Hazards, 104(2), 1581-1596. https://doi.org/10.1007/s11069-020-04234-y

[4] Planinsic, G. \& Etkina, E. (2019). Framework for using modern devices in introductory physics courses. European Journal of Physics, 40(6), 065702. https://doi.org/10.1088/1361-6404/ab3e26

[5] Marchese, A. J., Ramachandran, R. P., Hesketh, R. P., Schmalzel, J. L., \& Newell, H. L. (2003). The competitive assessment laboratory: introducing engineering design via consumer product benchmarking. IEEE Transactions on Education, 46(1), 197-205. https://doi.org/10.1109/te.2002.808216

[6] Wagner, J. \& Knaub, K. (2009, June 14-17). Time keeping experiments for a mechanical engineering education laboratory sequence. ASEE Annual Conference \& Exposition. Austin, Texas, USA. https://doi.org/10.18260/1-2--4758

[7] Mihajlović, G., Gašić, M., Savković, M., Mitrović, S., \& Tadić, B. (2017). Vibroplatform modelling with allowance for tribological aspects. Journal of Friction and Wear, 38(3), 184-189. https://doi.org/10.3103/s1068366617030102

[8] Miljojković, J., Bijelić, I., Vranić, N., Radovanović, N., \& Živković, M. (2017). Determining elastic modulus of the material by measuring the deflection of the beam loaded in bending. Tehnicki vjesnik - Technical Gazette, 24(4), 1227 1234. https://doi.org/10.17559/tv-20170609133537

[9] Tadic, B., Randjelovic, S., Todorovic, P., Zivkovic, J., Kocovic, V., Budak, I., \& Vukelic, D. (2016). Using a highstiffness burnishing tool for increased dimensional and geometrical accuracies of openings. Precision Engineering, 43, 335-344. https://doi.org/10.1016/j.precisioneng.2015.08.014

[10] Matejic, M., Tadić, B., Lazarevic, M., Misic, M., \& Vukelic, D. (2018). Modelling and simulation of a novel modular fixture for a flexible manufacturing system. International Journal of Simulation Modelling, 17(1), 18-29. https://doi.org/10.2507/ijsimm17(1)407

[11] Kostic, S., Miljojkovic, J., Simunovic, G., Vukelic, D., \& Tadic, B. (2021). Uncertainty in the determination of elastic modulus by tensile testing. Engineering Science and Technology, an International Journal. https://doi.org/10.1016/j.jestch.2021.05.002

[12] Vukelic, D., Todorovic, P., Simunovic, K., Miljojkovic, J., Simunovic, G., Budak, I., \& Tadic, B. (2021). A novel method for determination of kinetic friction coefficient using inclined plane. Tehnicki vjesnik - Technical Gazette, 28(2), 447-455. https://doi.org/10.17559/tv-20201101051835

[13] Stjepandić, J., Wognum, N., \& Verhagen, W. J. (Eds.). (2015). Concurrent engineering in the 21st century: Foundations, developments and challenges. Cham, Switzerland: Springer International Publishing. https://doi.org/10.1007/978-3-319-13776-6

[14] Tang, J., Xiong, B., Yang, C., Tang, C., Li, Y., Su, G., \& Bian, X. (2019). Development of an integrated power distribution system laboratory platform using modular miniature physical elements: A case study of fault location. Energies, 12(19), 3780. https://doi.org/10.3390/en12193780

[15] Reck, R. M. \& Sreenivas, R. S. (2016). Developing an affordable and portable control systems laboratory kit with a Raspberry Pi. Electronics, 5(3), 36. https://doi.org/10.3390/electronics5030036

[16] Andersen, A. L., Brunoe, T. D., \& Nielsen, K. (2019). Engineering education in changeable and reconfigurable manufacturing: Using problem-based learning in a learning factory environment. Procedia CIRP, 81, 7-12. https://doi.org/10.1016/j.procir.2019.03.002

[17] Çeven, S. \& Albayrak, A. (2020). Design and implementation of modular test equipment for process measurements in mechatronics education. Computer
Applications in Engineering Education, 28(2), 324-337. https://doi.org/10.1002/cae.22196

[18] Swider, J., Michalski, P., \& Wszołek, G. (2006). Laboratory support for the didactic process of engineering processes automation at the Faculty of Mechanical Engineering. Journal of Achievements in Materials and Manufacturing Engineering, 15(1-2), 199-206.

[19] Logman, P. S. W. M., Kaper, W., \& Ellermeijer, T. (2015). Evaluation of the learning process of students reinventing the general law of energy conservation. Eurasia Journal of Mathematics Science and Technology Education, 11(3), 479-504. https://doi.org/10.12973/eurasia.2015.1323a

[20] Cross, R. (2021). Effect of friction on a hula hoop. Physics Education, 56(3), 033001. https://doi.org/10.1088/1361-6552/abe173

[21] Allain, R. \& Williams, R. (2009). An analysis of a video game. The Physics Teacher, 47(2), 115-117. https://doi.org/10.1119/1.3072460

[22] Chakrabarti, S., Khaparde, R. B., \& Kachwala, A. H. (2020). Experimental study of the coefficient of rolling friction of the axle of a Maxwell's wheel on a soft horizontal surface. European Journal of Physics, 41(3), 035803. https://doi.org/10.1088/1361-6404/ab78a5

[23] Gainer, A. \& Waxman, M. (2021). Sliding on an Arbitrarily Shaped Incline with Friction. The Physics Teacher, 59(2), 117-119. https://doi.org/10.1119/10.0003466

[24] Lindén, J., Källman, K. M., \& Lindberg, M. (2021). The rolling elliptical cylinder. American Journal of Physics, 89(4), 358-364. https://doi.org/10.1119/10.0002362

[25] Chou, N., Hsu, C. C., \& Shen, J. L. (2020). Determining Earth's gravitational acceleration by free fall method with the presence of air resistance. Physics Education, 56(1), 015014. https://doi.org/10.1088/1361-6552/abc797

[26] Siebert, C., DeStefano, P. R., \& Widenhorn, R. (2019). Comparative modeling of free fall and drag-enhanced motion in the classical physics drop experiment. European Journal of Physics, 40(4), 045004. https://doi.org/10.1088/1361-6404/ab1fbc

[27] Yuksel, T., Walsh, Y., Magana, A. J., Nova, N., Krs, V., Ngambeki, I., Berger, E. J., \& Benes, B. (2019). Visuohaptic experiments: Exploring the effects of visual and haptic feedback on students' learning of friction concepts. Computer Applications in Engineering Education, 27(6), 1376-1401. https://doi.org/10.1002/cae.22157

[28] Jeremić, B., Vukelić, D., Todorović, P. M., Mačužić, I., Pantić, M., Džunić, D., \& Tadic, B. (2013). Static friction at high contact temperatures and low contact pressure. Journal of Friction and Wear, 34(2), 114-119. https://doi.org/10.3103/s1068366613020037

[29] Todorović, P. M., Blagojević, M., Vukelić, D., Mačužić, I., Jeremić, M., Simić, A., \& Jeremić, B. (2013). Static coefficient of rolling friction under heating. Journal of friction and wear, 34(6), 450-453. https://doi.org/10.3103/s1068366613060123

[30] Luković, M. (2019). The influence of surface temperature on the coefficient of static friction. The Physics Teacher, 57(9), 636-638. https://doi.org/10.1119/1.5135798

[31] Bijelić, I., Mor, N., Živković, M., Tubin, V., \& Stožinić, T. (2017). The influence of the contact pressure on the value of the coefficient of friction. Tribology in Industry, 39(2), 255259. https://doi.org/10.24874/ti.2017.39.02.13

[32] Tadić, B., Jeremić, B., Vukelić, D., Mitrović, S., \& Erić, M. (2011, May 11-13). Development of tribometer and measurement results of static coefficient of friction sliding and coefficient of rolling friction by principle steep plane. 12th International Conference on Tribology -SERBIATRIB '11. Kragujevac, Serbia.

[33] Zhuravlev, V. P. (2013). On the history of the dry friction law. Mechanics of solids, 48(4), 364-369. https://doi.org/10.3103/s002565441304002x 
[34] Euler, L. (1750). Sur le frottement des corps solides. Memoires de l'academie des sciences de Berlin, 4, 122-132.

[35] Batchelor, C. K. \& Batchelor, G. K. (2000). An introduction to fluid dynamics. Cambridge, UK: Cambridge university press.

\section{Contact information:}

\section{Jasmina MILJOJKOVIC, MSc}

(Corresponding author)

University of Kragujevac, Faculty of Engineering,

Sestre Janjić 6, 34000 Kragujevac, Serbia

E-mail: jasmina.miljojkovic@fink.rs

Vladimir KOCOVIC, PhD, Assistant Professor

University of Kragujevac, Faculty of Engineering,

Sestre Janjic 6, 34000 Kragujevac, Serbia

E-mail: vladimir.kocovic@kg.ac.rs

Milentije LUKOVIC, PhD, Assistant Professor

University of Kragujevac, Faculty of Technical Sciences Cacak,

Svetog Save 65, 32102 Cacak, Serbia

E-mail: milentije.lukovic@gmail.com

\section{Aleksandra ZIVKOVIC, MSc}

University of Kragujevac, Faculty of Engineering,

Sestre Janjić 6, 34000 Kragujevac, Serbia

E-mail: aleksandra.caki.zivkovic@gmail.com

Katica SIMUNOVIC, PhD, Full Professor

University of Slavonski Brod, Mechanical Engineering Faculty in Slavonski Brod

Trg Ivane Brlic Mazuranic 2, 35000 Slavonski Brod, Croatia

E-mail: ksimunovic@unisb.hr 